\title{
California Verbal Learning Test: The Normative Study of Turkish Adult Sample
}

\author{
(D) Aynur Feyzioğlu \\ Department of Clinical Psychology, University of Health Sciences, Turkey
}

\begin{abstract}
Introduction: California Verbal Learning Test (CVLT) was developed by Delis et al. for the need for a comprehensive evaluation of verbal learning and memory. To employ CVLT in assessments carried out in Turkey for preventive purposes, the test's normative data were crucial. Therefore, this study aimed to identify the normative values as gender, age and education level of CVLT for the healthy adults in Turkey.

Methods: 180 healthy individuals (Gender: 90 female and 90 male; Age groups: 17-64 ( $n=90)$ and 65-88 ( $n=90)$ ) participated in the present study.

Results: Normative data from all different subgruops (depending on age and gender) are generated.

Discussion and Conclusion: The clinical application and scientific researches using CVLT in Turkey can be better interpreted with the help of acquired normative data.

Keywords: California Verbal Learning Test, CVLT; normative data; Turkish population.
\end{abstract}

$V_{s}$ erbal memory and learning were studied by defined stimulus and response as a form of behaviorist way ${ }^{[1]}$. The impairment in verbal memory could be observed in mental disorders, such as schizophrenia, substance-use disorders, mild cognitive impairment, Alzheimer's disease, body dysmorphic disorder, Korsakoff syndrome, and multiple sclerosis ${ }^{[2-7]}$.

California Verbal Learning Test (CVLT) was developed by Delis et al. ${ }^{[8]}$ for the need for comprehensive evaluation of verbal learning and memory. It is crucial to have normative data for CVLT in the Turkish population to examine verbal memory and learning procedures of the patients and detect distinguished processes, thus, destructive outcomes may be prevented by this means. The general format and purpose of CVLT are similar to Öktem Verbal Memory Pro- cedure Test ${ }^{[9]}$, which was studied with the normative sample in Turkey. CVLT evaluates semantic organization, interference and proactive interference in addition to Öktem Verbal Memory Procedure Test. From this aspect, CVLT, being different from other assessment tools, would be able to examine multiple cognitive and verbal memory units using only one instrument ${ }^{[8]}$. Learning and memory measured in CVLT is a comprehensive evaluation, assessing not only the general memory functions but also the learning characteristics, recall consistency, and recognition tests ${ }^{[10]}$.

The neuropsychological assessment which is discussed in detail covers many aspects: in addition to brain activation, how it influences behaviors, specific brain disorders, and behavioral problems. Moreover, to examine scientific researches, the tests and techniques used should be valid 
and reliable, including sensitivity levels ${ }^{[11]}$. The variables, such as age, gender, hand preference, and education level, are related to the brain functions, as well as neuropsychological functions ${ }^{[12]}$. This emphasizes the importance of using standardized tests while evaluating cognitive functions. Therefore, this study aims to identify the normative values as gender, age and education level of CVLT for the healthy adults in Turkey. In this way, the clinical application of the CVLT could pave the way for our community.

\section{Materials and Methods}

\section{Participants}

There were 180 participants composed of 90 females and 90 males participated in the current study. Age groups of participants were 17-64 $(n=90)$ and 65-88 $(n=90)$. Participants' education levels were low education level (graduated from primary school or dropped secondary school) and medium/upper education level (graduated from secondary school, high school, college or university). This study was conducted with healthy adults. Ethical permission was given by the Department of Neurology Medicine Faculty, Istanbul University. The exclusion criteria for being healthy were having no neurological, psychiatric, systemic diseases and/or using anti-cholinergic, and narcotic-hypnotic medication. The descriptive features of the participants for each group are shown in Table 1.

\section{Materials}

California Verbal Learning Test (CVLT) includes the list learning task in which participants are asked to remember the words in three ways, namely, free recall, cued recall and recognition ${ }^{[13]}$. The translation of the CVLT used in the current study was a form of translation of Prof. Dr. Hakan Gürvit in the Department of Neurology Medicine Faculty,

Table 1. The numerical distribution of participants as age and education level

\begin{tabular}{lccc}
\hline Age and education level & $\mathbf{n}$ & Mean & SD \\
\hline $\begin{array}{l}\text { 17-64 range and Low (5 years) } \\
\quad \text { Female }\end{array}$ & 15 & 41 & 14.96 \\
$\quad$ Male & 15 & 42.6 & 15.14 \\
$\begin{array}{l}\text { 17-64 range and Medium/High (8-21 years) } \\
\text { Female }\end{array}$ & & & \\
$\quad$ Male & 30 & 41.93 & 12.88 \\
65-88 range and Low (5 years) & 42.9 & 13.39 \\
$\quad$ Female & 15 & 72.47 & 5.29 \\
$\quad$ Male & 15 & 72.73 & 6.06 \\
65-88 range and Medium/High (8-21 years) & & & \\
$\quad$ Female & 30 & 72.63 & 5.02 \\
$\quad$ Male & 30 & 73.53 & 6.53 \\
\hline
\end{tabular}

Istanbul University.

The test includes four parts consisting of sixteen words (four fruits, four plants and spices, four clothing, and four tools). These words are presented in the format of a shopping list. According to the procedure, short delay and long delay free recall applications (category cues help recalling) and 44 words for recognition application in addition to the presentation of 16 words are presented ${ }^{[14]}$.

The short delay free recall application, which is mentioned above, is the B list named as "Tuesday List" is the reason for delay. Tuesday List is similar to Monday List as it includes fruit and plant or spices. Additionally, it includes two categories as fish types and kitchen utensils. The long delay free recall application is administered after 20 minutes.

In the application of the test, A Monday List was read to the participant and the participant was asked to recall the words, the answers were recorded. This application was repeated for five times. After the fifth trial, B Tuesday List was read once, and the answers were recorded. The participant was asked to recall the words from the Monday List after 20 minutes delay. The cues were used for the missing words and the examiner told the participant that "Tell me the ones from the Monday List (category names are told, respectively, such as clothes) group." This procedure was practiced for the other three (spices, fruit and tools) categories in the same way.

Then, the last stage of the test started. The 44 words list was read one by one and the participant was asked to say yes if the word is one of the words from the Monday list.

California Verbal Learning Test does not only include the number of recalled words but also many qualities like learning and remembering strategies.

The sub-points of several qualities like the semantic clustering, recalling percentages of areas, learning slope, recalling consistency percentage, perseverations, interferences, false positives, separability, and response bias are calculated by a computer program.

Semantic clustering: The score of semantic clustering shows the quality of the participant's learning strategies, which is the ability of organizing the words in categories. Semantic clustering indicates the efficiency of learning strategies because sixteen words could be grouped into the four upper-level semantic units. Also, the low score in semantic clustering is related to the low performance of several other dimensions of this test.

Recalling percentages of areas: The participants typi- 
cally learn better the first and the last words on the list. The passive learning type is shown if the remembering of the first words is less and the remembering of the last words is fewer.

Learning slope: This shows the increasing number of words which are learned during the indicator trials. The tendency close to zero (0) might indicate that the participant reaches learning plateau quickly, the tendency level more than one (1) indicates the greater increase during remembering from trial to other trial.

Recalling consistency percentage: This indicator gives the percentage of any remembered words in the first four trials. Low remembering consistency percentage shows that the learning is random and disorganized; it might represent a need for formulating the learning planning and the maintenance difficulty of the participant.

Perseverations: Perseverations mean that the participant repeats the word he/she said in the same trial.

Interferences: Increased number of the interferences (the words not in the target list) may indicate the differentiation of the answers whether are related to the subject or not. The interference in which is the previous answer of the same category may show an intact semantic process but also there is impairment in differentiating newly learned pieces from other category units.

The indicators of the recognition may be in the following way:

False positives: High number of false positives may indicate one of these options: either difficulty in differentiating the target words from non-target words or the tendency to answer as Yes. The most impaired performance of the high false positives could be pointed out with the words in neither of the two lists. On the other hand, the false positives as a few $\mathrm{B}$ list words indicate better performance.

Discriminability: It indicates the ability of differentiating false positives and target words of the participant. A good memory performance is shown by a higher discriminability percentage.

Response bias: The ideal score is zero ( 0 ) and it means that "Yes" to sixteen target words, "No" to all false positives. The point getting close to +1 or -1 indicates a bias towards saying "Yes" or "No" responses, respectively.

\section{Application}

The tests were applied individually to each participant. The participants were informed about this study while avoiding cues about the tests. The participant and the examiner worked alone in a place that was possibly free from physical stimuli like heat, light, or sound. Any observer was not allowed to prevent the performance anxiety and the best performance of the participant was tried to be achieved.

\section{Statistical Analysis}

In the present study, IBM SPSS version 14 was used to analyze the collected data. Data were analyzed using the descriptive analysis to find the arithmetic mean, median, standard deviation, minimum and maximum values and percentile values of gender, age and education level for California Verbal Learning Test.

\section{Results}

The arithmetic mean, median, standard deviation, minimum and maximum values and percentile values of gender, age and education level for the California Verbal Learning Test were specified. Descriptive statistic tables of CVLT as gender, age and education level groups are presented below (Tables 2, 9).

\section{Discussion}

This study aims to specify descriptive statistics and percentile normative values for gender, age and education level for CVLT in a healthy adult Turkey sample. The data were collected from one hundred eighty adults after translation study and the descriptive statistical analyses were examined. The descriptive statistical analysis of the arithmetic mean, standard deviation and percentile normative values of CVLT was specified. Understanding of cognitive functions in neuropsychological assessments provides important details for both normative values and neurological disorders. Also, using reliable and valid tests are significantly practical and valuable to examine each person's cognitive profile.

Percentile-normative values were determined and the use of the California Verbal Learning Test in clinical applications was made possible. It was significant considering the specified percentile-normative values of gender, age and education level while using CVLT for diagnosis purposes. The following studies for the reliability and validity of CVLT could help test usage in a more psychometrically confidential way.

The score of CVLT in the long delay part could predict subjective memory problems supported by neuroimaging findings and affect depression level. Thus, this test could be used for prevention and early detection ${ }^{[16]}$. 


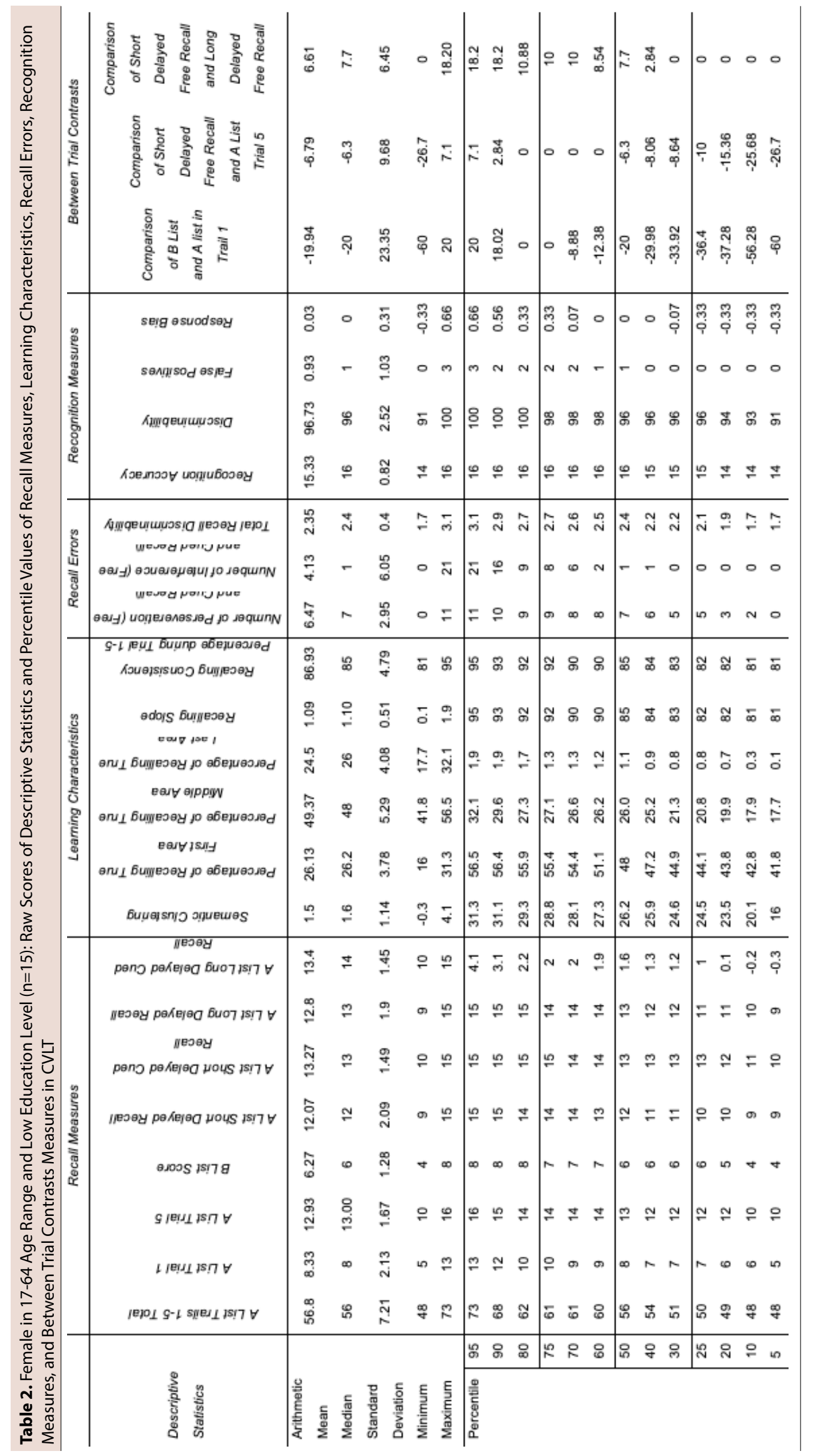




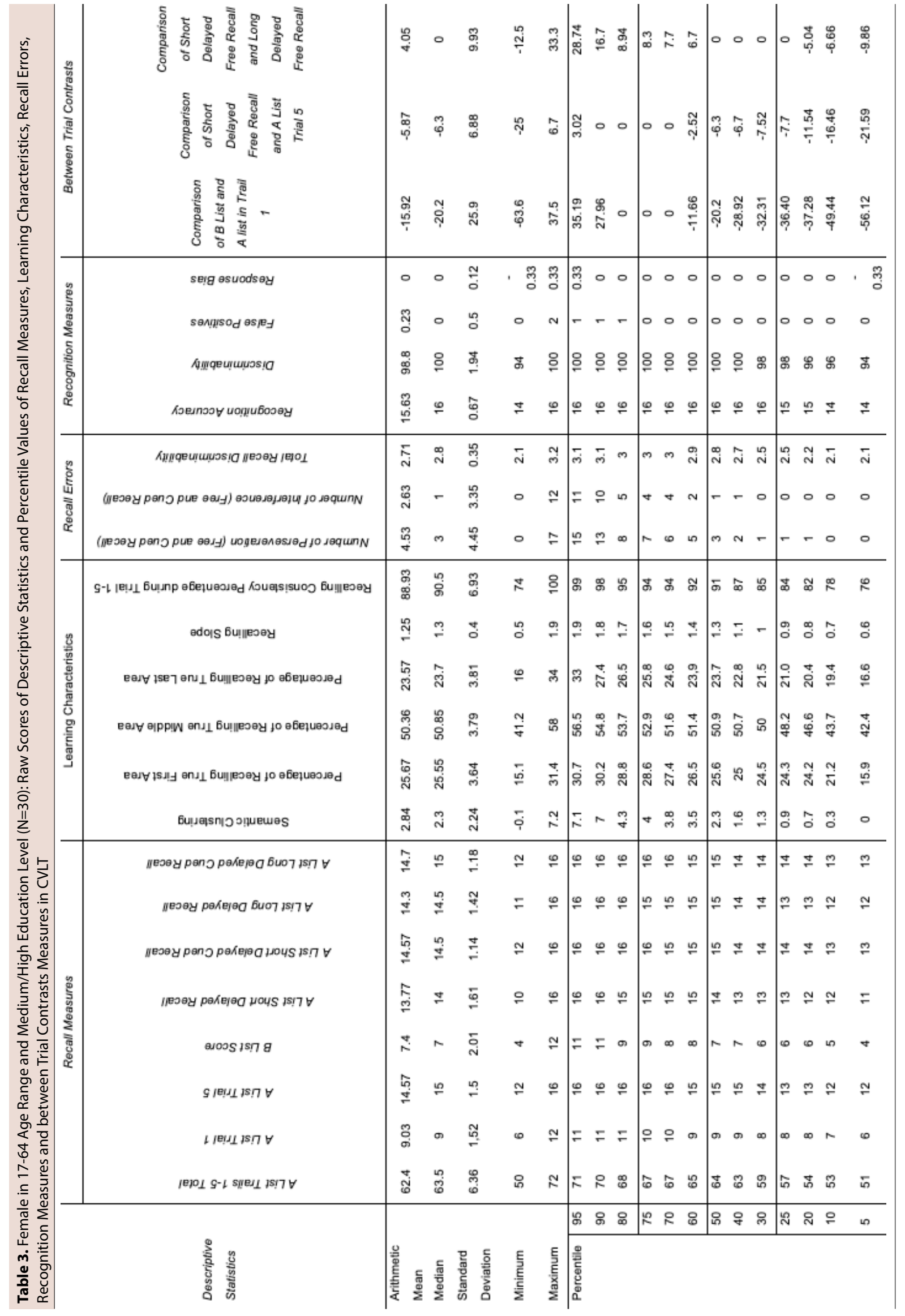




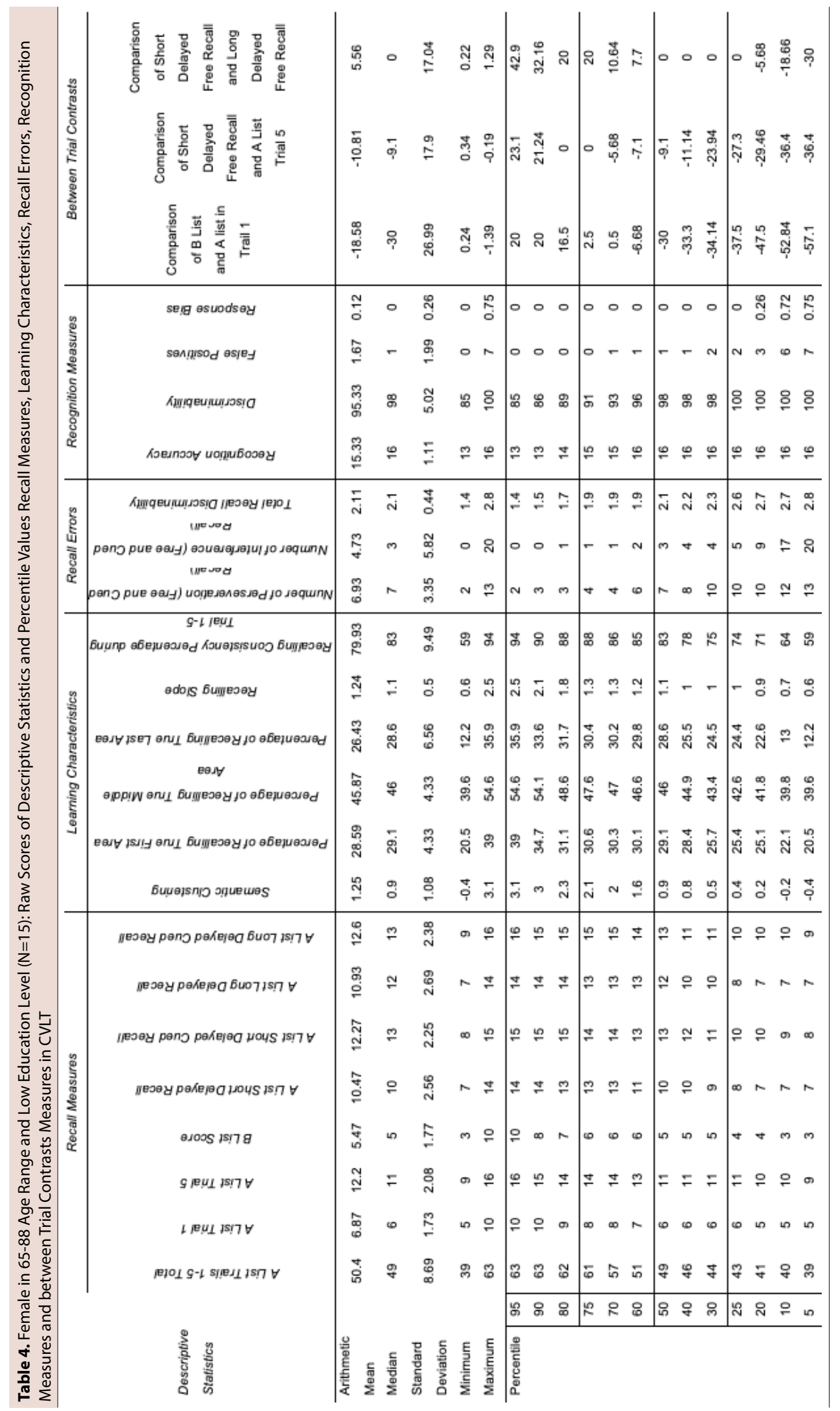




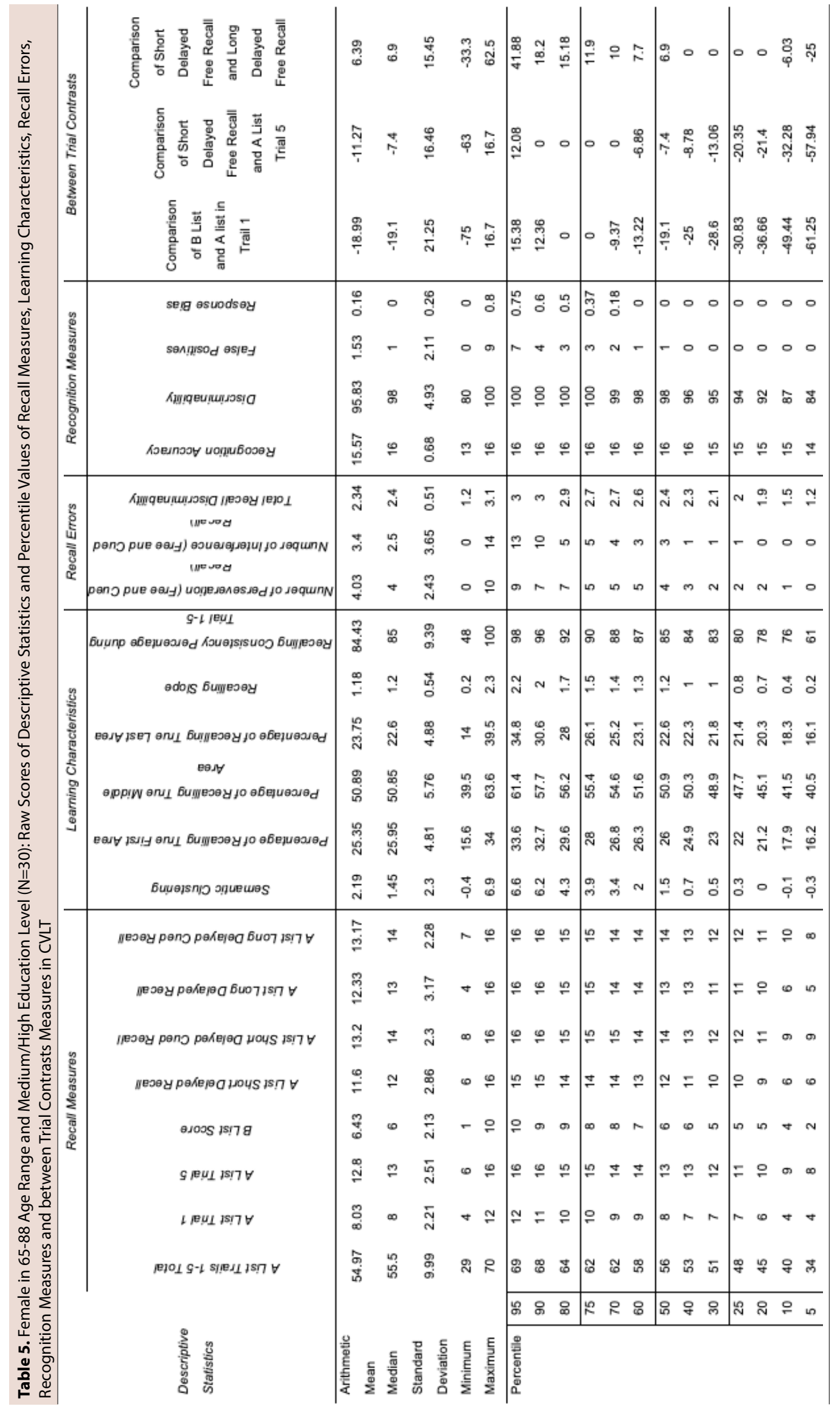




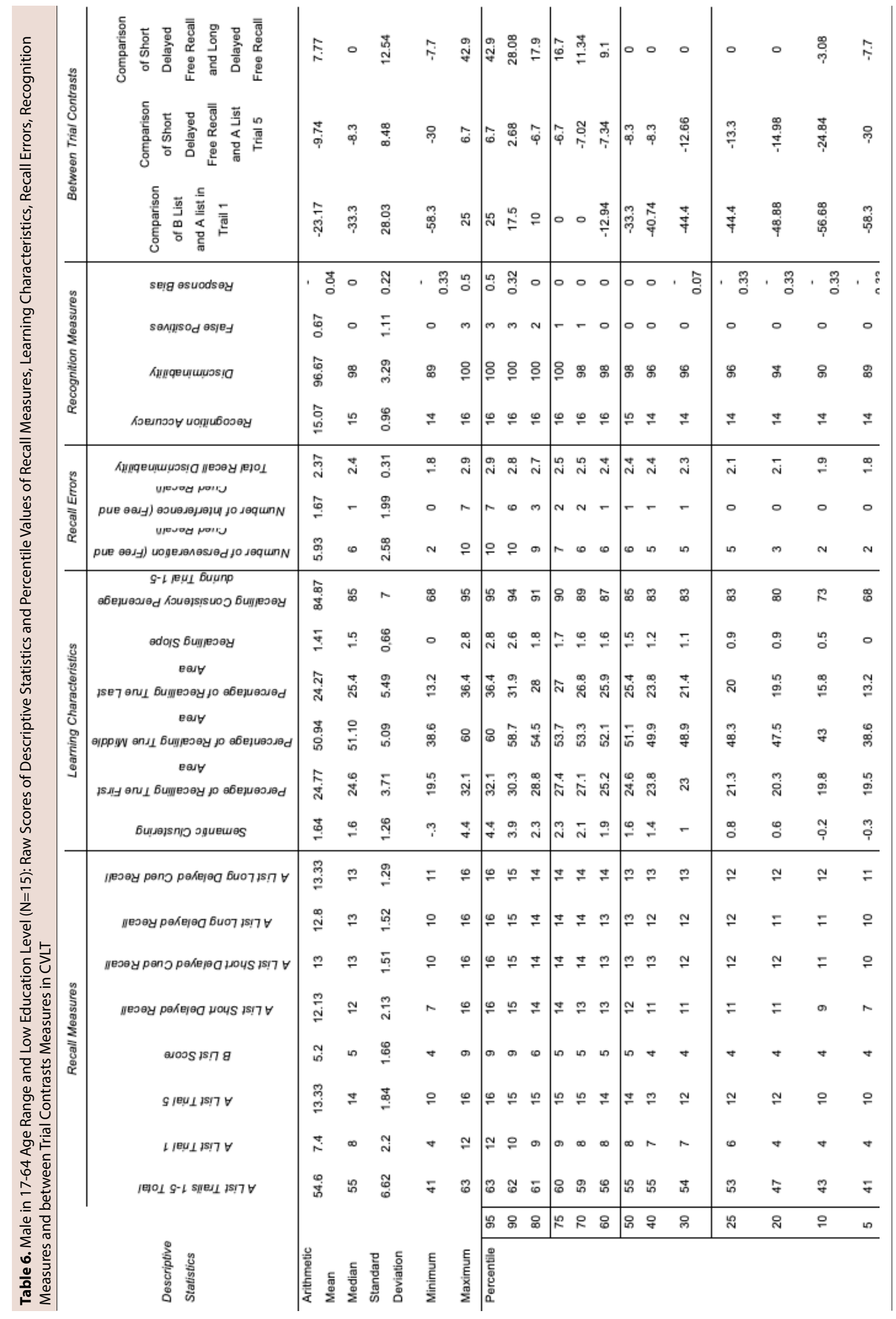




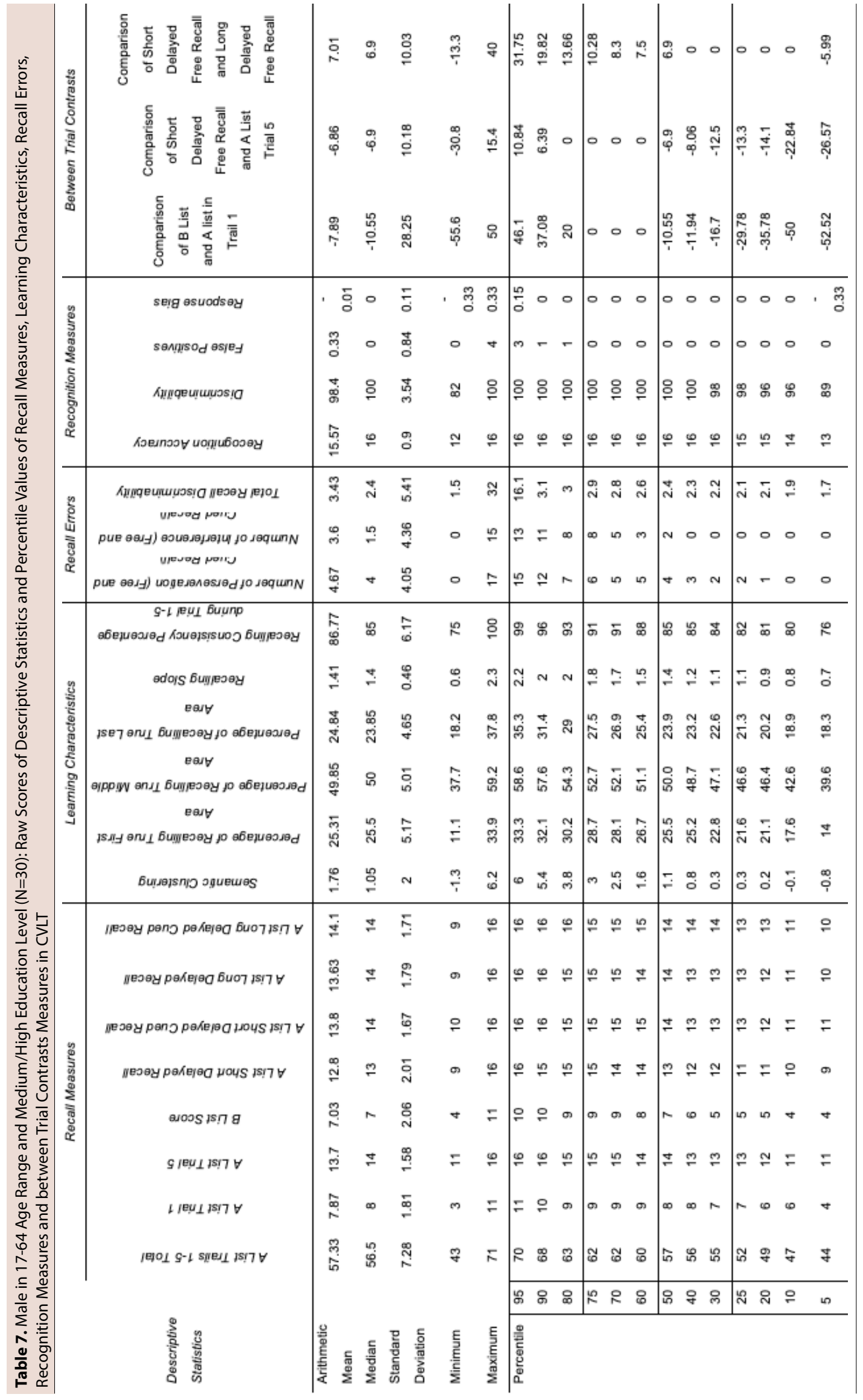




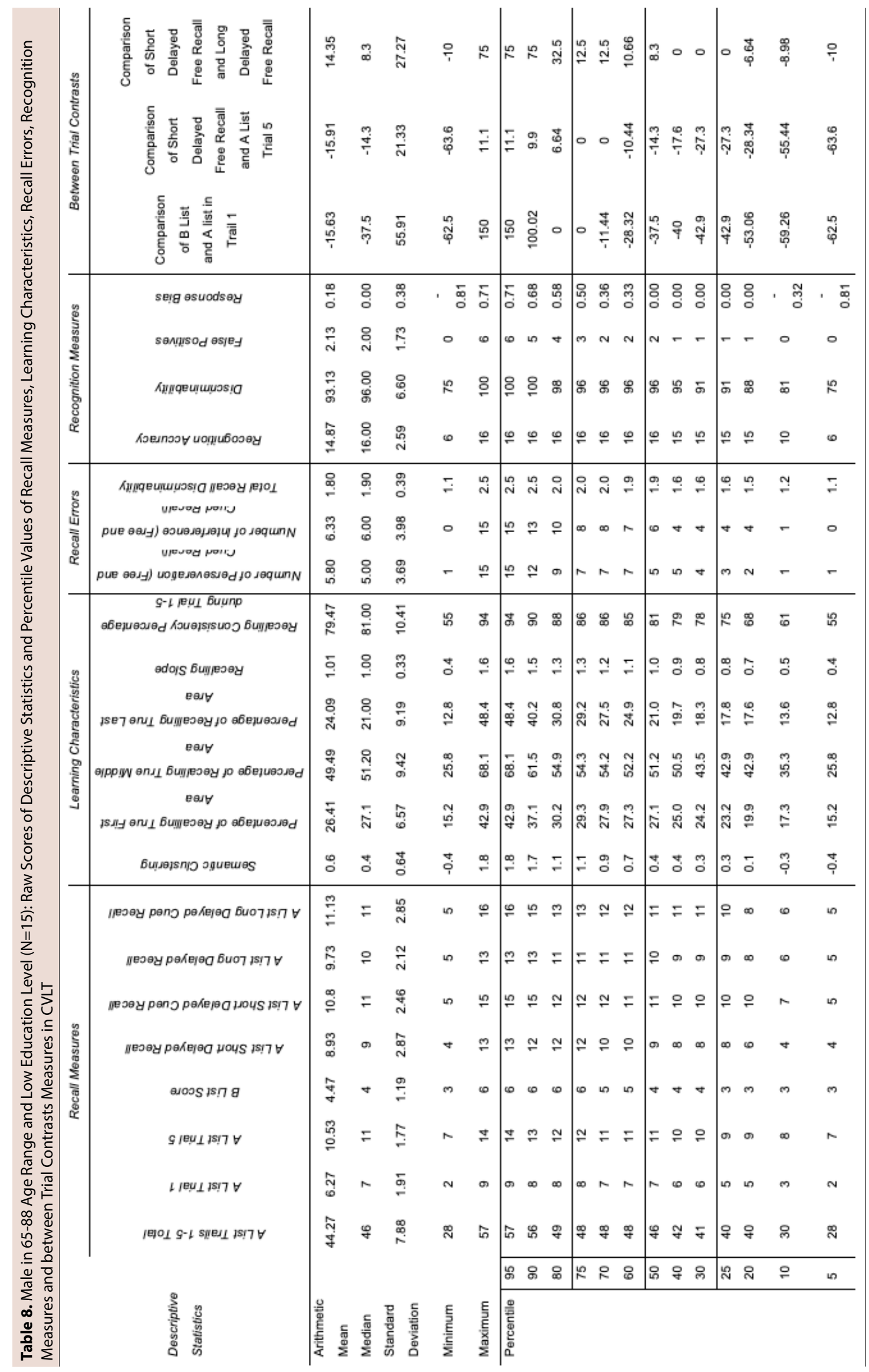




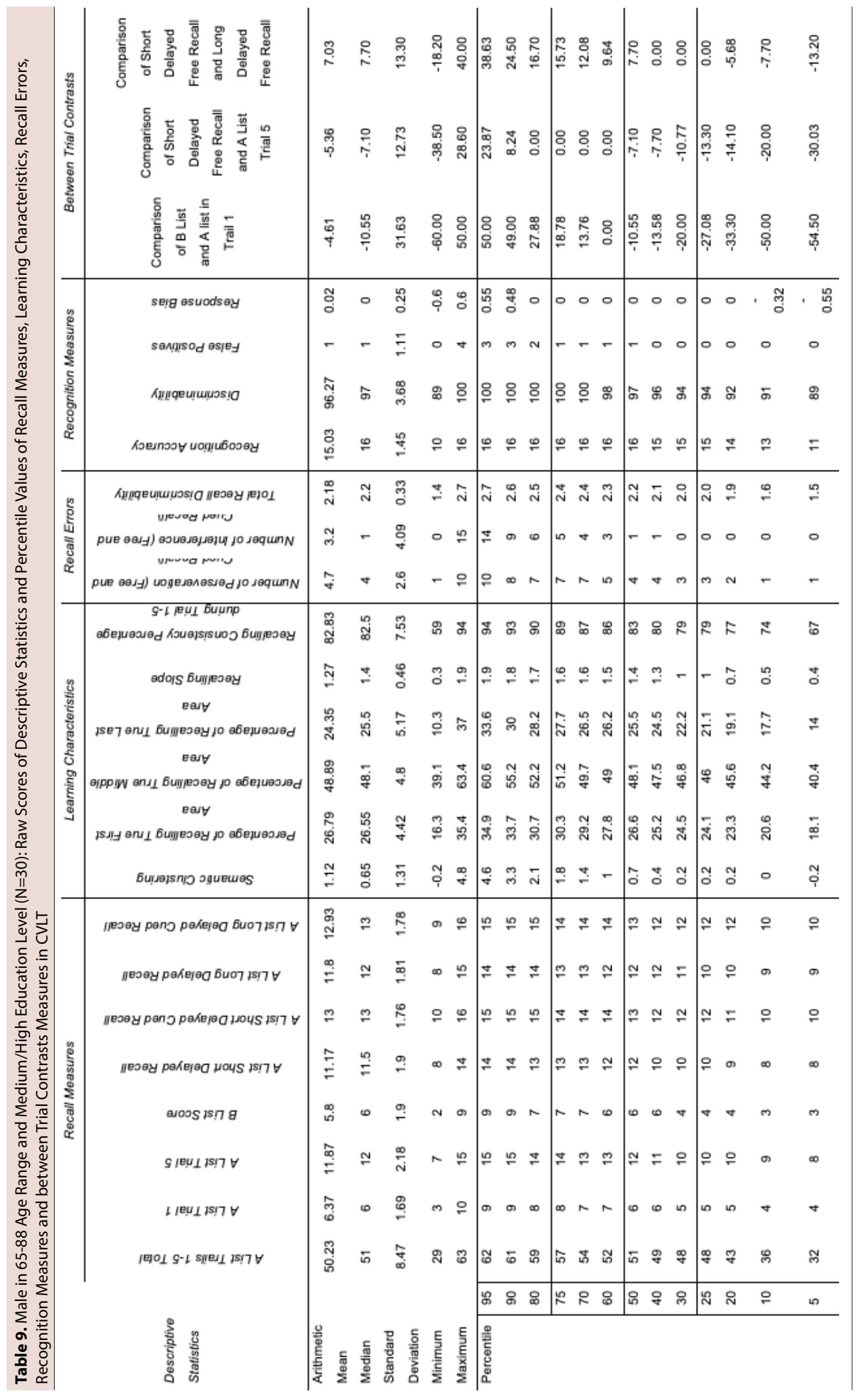


Peer-review: Externally peer-reviewed.

Conflict of Interest: None declared.

Financial Disclosure: The authors declared that this study received no financial support.

\section{References}

1. Radvansky GA. Human Memory. New York: Routledge; 2017.

2. Ulaş $H$, Taşlıca $S$, \& Alptekin K. Şizofrenide Nörofizyolojik ve Nörokognitif Genetik Belirleyicilerin (Endofenotip) Yeri. Klinik Psikiyatri Dergisi 2008;11:12-9.

3. Solowij N, Jones KA, Rozman ME, Davis SM, Ciarrochi J, Heaven $P C$, et al. Verbal learning and memory in adolescent cannabis users, alcohol users and non-users. Psychopharmacology (Berl) 2011;216:131-44. [CrossRef]

4. Şentürk G. Hafif Kognitif Bozukluk ve Erken Evre Alzheimer Hastalarında İç görü Mekanizmalarının Nöropsikolojik Testler ve Volumetrik MR Dataları ile Karşılaştırmalı Olarak Araştırılması. İstanbul: İstanbul Univ; 2013.

5. Kıvrak TA. Beden Dismorfik Bozukluğunda Klinik, Sosyodemografik Verilerin İncelenmesi ve Bilişsel İşlevlerin Nöropsikolojik Testlerle Değerlendirilmesi. İstanbul: İstanbul Univ; 2009.

6. Kessels RP, van Loon E, Wester AJ. Route learning in amnesia: a comparison of trial-and-error and errorless learning in patients with the Korsakoff syndrome. Clin Rehabil 2007;21:90511. [CrossRef]

7. Barcellos LF, Bellesis KH, Shen L, Shao X, Chinn T, Frndak S, et al. Remote assessment of verbal memory in MS patients using the California Verbal Learning Test. Mult Scler 2018;24:354-7.

8. Delis DC, Kramer HJ, Kaplan E, Ober AB. California Verbal Learning Test Manual. The Psychological Corporation Har- court Brace Jovanovich. New York, 1987. [CrossRef]

9. Öktem Tanör Ö. Öktem Sözel Bellek Süreçleri Testi (ÖktemSBST) El Kitabı. Ankara: Türk Psikologlar Derneği Yayınları, 2011.

10. Numan B, Sweet JJ, Ranganath C. Use of the California Verbal Learning Test to detect proactive interference in the traumatically brain injured. J Clin Psychol 2000;56:553-62. [CrossRef]

11. Lezak MD, Howieson DB, Loring DW, Fischer JS. Neuropsychological Assessment. USA: Oxford University Press, 2012.

12. Goldstein G. Historical Perspectives. In: Puente AE, McCaffrey RJ. Handbook of Neuropsychological Assessment: A Biopsychosocial Perspective. New York: Plenum Press; 1992: 1-9.

13. Jurik J. Differentiating Frontal variant Frontotemporal Dementia from Alzheimer's Disease Using A Brief Neuropsychological Battery. Palo Alto University, Pacific Graduate School of Psychology. Doctor of Philosophy in Psychology, 2010. Available at: https://pqdtopen.proquest.com/doc/866198825.htmI?FMT=ABS.

14. Mitrushina NM, Boone BK, D'Elia FL. Handbook of Normative Data for Neuropscyhological. New York: Oxford University Press, 1999.

15. Argento O, Pisani V, Incerti CC, Magistrale G, Caltagirone C, Nocentini U. The California Verbal Learning Test-II: normative data for two Italian alternative forms. Clin Neuropsychol 2015;28:S42-54. [CrossRef]

16. Aguirre C. Subjective Memory Complaints of the Oldest-Old: SubclinicalandNeuropsychological Predictorsinthe90+Study. University of Washington, Public Health. Master Thesis, 2018. Retrieved Available at: http://search.ebscohost.com/login. aspx?direct=true\&db=ddu\&AN=7E5C9767FF639A43\&site=ehost-live. 